\title{
A transparência do concreto: a linguagem imagística de Iracema
}

André Cabral de Almeida Cardoso Universidade Federal Fluminense

Resumo: Este artigo parte da análise de um trecho do romance Lucíola, de José de Alencar, para chegar a uma discussão mais ampla dos similes empregados por Alencar em seus romances indianistas e, mais especificamente, em Iracema. A passagem de Lucíola analisada oferece uma das chaves para compreender a linguagem imagística usada por Alencar nos romances indianistas: a busca de uma linguagem transparente, calcada em imagens e associada ao primitivo e à natureza. Este trabalho procura demonstrar que a busca por esse tipo de linguagem faz parte de uma longa tradição sentimental que tem sua origem na Europa do século XVIII e que ainda influencia a obra de Alencar. Convenções sentimentais ligadas à sensibilidade e à empatia estariam por trás dos similes criados por Alencar em Iracema, que seriam um exemplo de seu desejo de criar uma linguagem expressiva que apagaria a intermediação da linguagem verbal.

Palavras-chave: Transparência, Imagens, Literatura sentimental.

Num determinado ponto de Lucíola, a protagonista do romance de Alencar - depois de arranjar um novo amante para afastar as suspeitas de que ela 
estava sustentando Paulo, o narrador do romance e seu verdadeiro amor - procura demonstrar a este que não havia tido relações sexuais com outro e, portanto, tinha se mantido fiel. Trata-se de um momento crucial da narrativa, pois marca o início da redenção de Lúcia, que começa a revelar a Paulo a sua inocência fundamental, apesar dos anos que passara trabalhando como cortesã:

Fora o acaso ou uma doce inspiração que arranjara o traje puro e simples que ela trazia? Tudo era branco e resplandecente como a sua fronte serena: por vestes cassas e rendas; por jóias somente pérolas. Nem uma fita, nem um aro dourado, manchava essa nítida e cândida imagem. Creio antes na inspiração. Lúcia tinha no coração o germe da poesia ingênua e delicada das naturezas primitivas, que se revela por um emblema e por uma alegoria. Ela me dizia no seu traje o que nunca se animaria a dizer-me em palavras, que estava tão pura como eu a tinha deixado, do contato de outro homem.

É um trecho marcante, não só pela sua importância no enredo, mas também porque resume em poucas linhas o caráter de Lúcia, cuja construção está no cerne de Lucíla como um todo. Além disso, reúne, de forma extremamente concentrada, várias das preocupações centrais de Alencar ao desenvolver essa narrativa, muitas delas oriundas de uma longa tradição sentimental que se consolida na Europa a partir de meados do século XVIII. Temos aqui, por exemplo, o elogio à simplicidade e à ausência de ostentação, tão caras ao romance sentimental, e que na Europa estavam ligadas ao estabelecimento de uma moral burguesa calcada nos valores de economia, parcimônia e horror ao luxo (associado a uma aristocracia em decadência) de uma classe média em ascensão. ${ }^{2}$ Do mesmo modo, está

\section{ALENCAR. Luciola, p. 80.}

2. Quanto à importância da cultura sentimental para o estabelecimento de uma moral burguesa na Inglaterra, ver G. J. Barker-Benfield, The Culture of Sensibility: Sex and Society in Eighteenth-Century Britain e Terry Eagleton, The Rape of Clarissa: Writing, Sexuality and Class Struggle in Samuel Richardson. David J. Denby, em Sentimental Narrative and the Social Order in France, 1760-1820, e Margaret Cohen, em The Sentimental Education of the Novel, discutem a importância da literatura sentimental para a solidificação de uma ideologia burguesa na França, enquanto John Mullan, em Sentiment and Sociability: The Language of Feeling in the Eighteenth Century, chama atenção para o papel do sentimentalismo na construção da sociabilidade no século XVIII. 
presente o destaque dado aos ideais de pureza e castidade, típicos de uma heroína sentimental. Sobretudo, está presente também a insistência na transparência de Lúcia, marcada na imagem "nítida" (e, portanto, clara) e "cândida" que ela apresenta, assim como na crença do narrador de que a protagonista se mostrava em seus trajes brancos e simples por inspiração, ou seja, de forma espontânea e não calculada, o que exclui qualquer possibilidade de fingimento.

Quando está vestido de forma adequada, o corpo de Lúcia - que, despido, era uma manifestação do desejo sexual descontrolado - pode representar a pureza que, de acordo com a lógica da narrativa de Lucíola, é estranha a ele e à qual ele se opõe. Ocorre, assim, uma curiosa inversão: o corpo de Lúcia, quando está nu, torna-se opaco e, quando vestido, torna-se transparente, apagando-se para se tornar uma expressão da alma da personagem. Isso acontece porque "quando a mulher se desnuda para o prazer, os olhos do amante a vestem de um fluido que cega"; 3 quando Lúcia se exibe num banquete promovido por um de seus antigos amantes, Paulo a compara a uma jumenta no cio que morde cavalos para excitá-los. ${ }^{4}$ O observador, assim, ou é cegado pelo desejo, ou se vê confrontado com um corpo equivalente ao de um animal irracional, incapaz de qualquer sentimento além de sua irritação sexual. De qualquer forma, o olhar do observador se detém no corpo em si enquanto um objeto exclusivamente material. No entanto, quando Lúcia se veste de branco para demonstrar a sua pureza, o seu corpo se torna um emblema que representa aquilo que ele em princípio deveria ocultar. Ao contrário do corpo da jumenta, que está limitado a si mesmo, embora exija uma irritação constante, o corpo de Lúcia adquire um significado que transcende seu aspecto físico. Quando esse processo se aprofunda, o corpo de Lúcia se torna literalmente transparente, pelo menos aos olhos do narrador: "Calei-me, admirando com respeitosa ternura o rosto puro e cândido que entre a alvura do linho e no repouso das paixões tomara uma diáfana limpidez". Esse corpo pode ser redimido sempre que se torna diáfano e a inocência fundamental de Lúcia vem à tona trata-se, é claro, de um corpo que deve desaparecer, pelo menos até certo ponto. Ao mesmo tempo, trata-se de um corpo que, vestido de forma apropriada ou realizando ações adequadas (como enrubescer, por exemplo), funciona como o

3. ALENCAR. Luciola, p. 43.

4. ALENCAR. Luciola, p. 44.

5. ALENCAR. Luciola, p. 98. 
fundamento da comunicação. De qualquer forma, pode-se argumentar que a tensão entre ausência e presença permanece, pois o corpo se torna um símbolo que deve ir para além de si mesmo a fim de expressar uma verdade moral e psíquica. É muito significativo que ele diga algo que Lúcia não se atreveria a dizer a Paulo com palavras. Não se trata apenas de uma questão de recato (outro elemento da moral burguesa que a literatura sentimental associava com insistência às suas heroínas); ao se oferecer como uma imagem, o corpo de Lúcia torna-se um meio de comunicação bem mais eficiente e confiável do que as palavras.

Como Patricia Meyer Spacks observa, a literatura sentimental, na qual a noção de sensibilidade - a capacidade de reagir a estímulos sensoriais externos, principalmente à visão dos sinais de sofrimento no outro - ocupava uma posição central, perseguia uma fantasia de total acesso ao estado emocional de cada indivíduo, uma vez que os sinais de qualquer transtorno afetivo, assim como as reações do observador sensivel desse transtorno, se manifestavam no próprio corpo através de fenômenos físicos, como o choro, o enrubescimento e o desmaio. Esse tipo de reação, espontânea e involuntária, era essencialmente visível e observável, e a interioridade do indivíduo vinha inscrita na superfície do corpo, que se tornava transparente ao expressá-la de forma imediata. Assim, para Spacks, a sensibilidade exige uma certa performance, na qual sentimentos são exibidos diante de um espectador que deveria reagir a eles. No entanto, esse processo acarreta uma ambiguidade: ele pode ser mal interpretado, ou as manifestações emocionais atribuídas às causas erradas. ${ }^{6}$ Pior ainda, essas manifestações de sentimento podem ser um embuste intencional. Alencar procura evitar esse risco recorrendo à autoridade de seu narrador, que nos garante que Lúcia, ao escolher suas vestes brancas, estava agindo por instinto e, portanto, de forma espontânea. Além disso, ele procura controlar ainda mais a interpretação do leitor ao nos mostrar, logo nas primeiras páginas do romance, Lúcia como uma personagem cuja pureza não é fruto da dissimulação. Ela nos é apresentada pela primeira vez à entrada da igreja da Glória durante uma festa religiosa, olhando para as nuvens no horizonte. Inconsciente de tudo o que a cerca e de estar sendo observada, ela exala inocência e castidade. Seu rosto, descrito como "puro e diáfano", desde já associa Lúcia à ideia de transparência. Logo depois, ela é vista pelo narrador (mais uma vez, sem saber que está sendo observada) dando esmolas para os pobres, o que demonstra sua

6. SPACKS. Ambiguous Practices, p. 151, p. 160-61, p. 163. 
caridade, mais um traço desejável numa heroína sentimental. ${ }^{7}$ O fato de estar absorta e não ter consciência de que é vista pelo narrador é uma garantia de que a aparência de Lúcia não envolvia nenhum tipo de fingimento.

Todas essas ocasiões em que Lúcia se revela como uma imagem, principalmente no momento em que ela é apresentada pela primeira vez ao leitor, lembram os quadros discutidos por Michael Fried em seu livro sobre a pintura francesa do século XVIII. ${ }^{8}$ Fried se refere ao estabelecimento de um ideal de pintura entre as décadas de 1750 e 1770 - a mesma época em que se deu a consolidação da ficção sentimental - em que a figura representada parece completamente alheia à presença de um espectador que contempla o quadro. A enfática exclusão do espectador cria a ilusão de que as cenas mostradas nas pinturas estão ocorrendo naturalmente e de forma espontânea, de que não foram montadas para os propósitos da representação. A falta de consciência por parte da figura pintada de que está sendo observada - marcada por sua intensa absorção na atividade em que está engajada, ou até mesmo pelo sono - é, sobretudo, uma falta de consciência de sua condição como um objeto de representação. A negação da condição da pintura como um meio de representação provoca uma "leitura" alucinatória por parte do espectador, que é levado a imaginar que está em contado imediato com a figura mostrada no quadro, com a qual pode inclusive interagir, pois esta lhe é apresentada de forma transparente.

É possível comparar os efeitos e o processo de composição dessas pinturas ao recurso literário do tableau, muito comum nos romances sentimentais. Como Margaret Cohen explica em sua pequena poética da literatura sentimental, ${ }^{10}$ nos momentos em que os conflitos que estruturam o romance sentimental atingem um momento de crise, é comum que a narrativa se imobilize, oferecendo uma imagem da protagonista representando essa crise em seu próprio corpo. O exemplo citado por Cohen, retirado de Claire d'Albe, de Mme. Cottin, publicado em 1799, é ao mesmo tempo claro e típico da tradição sentimental: depois de confessar seu amor por Frédéric, um amor proibido, já que o rapaz é sobrinho de seu marido,

7. ALENCAR. Luciola, p. 14-15.

8. FRIED. Absorption and Theatricality: Painting and Beholder in the Age of Diderot.

9. Como faz David Marshall. Ver MARSHALL. The Surprising Effects of Sympathy: Marivaux, Diderot, Rousseau, and Mary Shelley, p. 36.

10. COHEN. The Sentimental Education of the Novel, p. 65-67. 
Claire se atira aos pés do jovem, prostrada e indefesa. O gesto é uma forma de Claire mostrar sua própria fragilidade e implorar que Frédéric se abstenha de tentar consumar seu amor e lançá-la à desonra. A imagem de Claire jogada aos pés de Frédéric, ao mesmo tempo em que a protagonista pede para que sua virtude seja poupada, resume num único quadro o conflito básico do romance, que trata da tensão entre o amor de Claire pelo rapaz e o seu dever enquanto esposa, ao qual Claire se apega com igual força. Essa imagem extremamente visual é muito eficiente, pois obtém de Frédéric o efeito desejado (ele abre mão de Claire e, portanto, de sua própria felicidade); ao mesmo tempo, ela comove o leitor, que é assaltado de forma imediata, num momento suspenso no tempo, por toda a carga emocional do conflito central do romance. David Denby se refere ao poder de concentração do tableau, que reúne numa única imagem o conteúdo emocional de toda uma sequência de eventos, assim como seu conteúdo moral, tornando-se uma unidade expressiva particularmente forte. ${ }^{11}$ O tableau, assim, age como um ponto privilegiado de transparência na narrativa, pois coloca às claras, na superfície da imagem, o apelo sentimental, os conflitos e o conteúdo moral de boa parte do relato, assim como a maneira pela qual estes são interiorizados pelos personagens.

A cena em que Lúcia se mostra a Paulo vestida de branco depois de seu banho purificador pode ser encarada como um tableau desse tipo, pois revela, através de uma imagem, a situação emocional e moral da personagem. Alencar parece confiar no caráter não linguístico desse tipo de comunicação para assegurar a sua transparência. Essa forma de representação pictórica é apresentada explicitamente pelo narrador como algo preferível à linguagem falada. Na lógica de Alencar, o caráter não linguístico dessa imagem lhe permite negar seu caráter arbitrário, uma vez que ela é associada a uma forma de expressão natural e primitiva, anterior à codificação claramente arbitrária de que depende a palavra e, mais ainda, a palavra escrita. Na verdade, estamos diante de uma tentativa de se livrar completamente do meio, de reduzir a linguagem escrita à evocação de uma imagem que supostamente transmite um significado imediato.

Ao discutir como a noção de transparência se desenvolve nos escritos de Rousseau e como ela é central no pensamento do filósofo, Jean Starobinski vê um processo semelhante de significação não verbal em ação, com o próprio Rousseau funcionando como sujeito significante. Segundo Starobinski, ao se

11. DENBY. Sentimental Narrative and the Social Order in France, 17601820 , p. 51. 
apresentar como uma "alma sensível", Rousseau ao mesmo tempo se apresenta como um ser transparente, pois todas as suas emoções são instantaneamente visíveis, comunicadas através de "sinais naturais" como o rubor, as lágrimas, os gestos e o olhar, que expressam seus sentimentos na superfície de seu próprio corpo. Starobinski explica que esse tipo de signo natural se manifesta ao mesmo tempo que o próprio sentimento, pois ambos compartilham da mesma substância, uma vez que o signo natural nada mais é do que a manifestação do sentimento no nível do corpo: "A agitação da paixão é e deseja ser imediatamente expressiva: o brilho do olhar é ao mesmo tempo a cólera e a linguagem que comunica a cólera". ${ }^{12}$ De acordo com Starobinski, ao longo do século XVIII, era comum opor os "signos naturais" aos "signos artificiais". ${ }^{13}$ Estes têm seu exemplo mais acabado na linguagem escrita, que é altamente convencional e abstrata. Para Rousseau, isso significava uma queda da linguagem primitiva, que transmitia a presença imediata do sentimento, e que era em grande parte onomatopaica, imitando o tom das paixões ou as sensações despertadas pela presença de um determinado objeto, além de se basear em imagens e sentimentos. ${ }^{14}$ Esse tipo de linguagem primitiva, na opinião de Rousseau, está mais próximo da natureza, já que o pensamento natural seria concreto $^{15}$ - daí a importância das imagens na linguagem primitiva, uma vez que elas seriam infinitamente mais concretas do que as abstrações da linguagem escrita moderna, e evocariam a presença de um objeto real. Como Martin Calder observa, a ideia de uma linguagem natural, baseada em gestos expressivos e, portanto, não arbitrários, como os signos naturais discutidos por Starobinski, era bastante comum no século XVIII. Outro lugar comum era associar esse tipo de linguagem a povos "primitivos" - incluindo os nativos das Américas - que estariam mais próximos à

12. "Le bouleversement de l'émotion est et se veut immédiatement expressif: l'étincellement du regard est à la fois la colère et le langage qui dit la colère." STAROBINSKI. Jean-Jacques Rousseau: La transparence et l'obstacle, suivi de Sept essais sur Rousseau, p. 180. Tradução minha.

13. STAROBINSKI. Jean-Jacques Rousseau: La transparence et l'obstacle, suivi de Sept essais sur Rousseau, p. 179.

14. STAROBINSKI. Jean-Jacques Rousseau: La transparence et l'obstacle, suivi de Sept essais sur Rousseau, p.178.

15. ROUSSEAu. Discours sur l'origine de l'inégalité, p. 149-50. 
natureza e às origens da humanidade e do discurso. ${ }^{16}$ Essa maneira de pensar seria amplamente absorvida pelo romance sentimental, que, influenciado por Rousseau, identificaria a natureza com o autêntico e o originário, e também com uma forma de expressão transparente.

Ao oferecer a própria Lúcia como um emblema ao se vestir de branco para Paulo, Alencar a associa explicitamente a uma manifestação dessa linguagem primitiva. Em vez de falar, ela expressa o que tem a dizer através de uma imagem, e os termos empregados por Alencar deixam claro que esta é a verdadeira forma de comunicação de Lúcia. É interessante observar que as palavras utilizadas pelo narrador de Alencar para se referir a Lúcia na passagem citada acima são um eco da maneira como Peri nos é apresentado em O Guarani. Assim como o índio, Lúcia é uma "natureza primitiva".

Se me detive tanto tempo nesse trecho relativamente curto de Lucíla, é porque ele oferece, de forma bastante concisa, a chave para compreendermos a linguagem que Alencar emprega em seus romances indianistas e que é um de seus maiores sucessos. Trata-se de uma linguagem calcada na constante evocação de imagens retiradas da natureza e que agem como termos de comparação para gestos, atitudes e conceitos que o narrador está tentando descrever para o leitor. Trata-se de uma linguagem essencialmente sensorial, principalmente no que diz respeito à sua evocação de percepções visuais, e, é claro, de uma linguagem essencialmente concreta que traduz um conceito abstrato numa imagem tangível.

Mais do que uma tentativa de dar expressão ao caráter brasileiro forjando uma linguagem tipicamente nacional ${ }^{17}$ ou do que um esforço puramente estético de criar uma linguagem original, ou ainda uma simples apropriação do estilo de um Chateaubriand, a insistência de Alencar em utilizar símiles e imagens concretas representa uma tentativa de criar uma linguagem transparente. A importância desse projeto para Alencar pode ser confirmada não só pelo seu esforço de aperfeiçoar seu estilo nos romances indianistas, mas também na presença

16. CALDER. Encounters with the Other: A Journey to the Limits of Language through Works by Rousseau, Defoe, Prévost and Graffigny, p. 36.

17. SANTIAGO. Alegoria e palavra em Iracema, p. 58. 
dessa tendência - ainda que bem mais esporádica do que nos romances indianistas - em toda a sua obra, mesmo nos romances urbanos. ${ }^{18}$

A linguagem imagística de Alencar se manifesta principalmente nos símiles que perpassam todos os seus romances indianistas. É em Iracema, porém, que o emprego desse recurso se dá de forma mais apurada, e nessa narrativa podemos ver com bastante clareza a ligação entre os símiles e a tradição sentimental que tanto influenciou a obra de Alencar. Aqui o símile transborda o discurso dos índios para se tornar um dos elementos formais que estruturam a narrativa. Os primeiros exemplos ocorrem logo no início do romance, inseridos na descrição de Iracema, com seus "cabelos mais negros que a asa da graúna e mais longos que seu talhe de palmeira". 19 O uso desses símiles bastante simples tem o efeito de associar Iracema imediatamente à natureza, na qual seu ser e seu próprio corpo estão inseridos. Antes que símiles mais longos e mais elaborados sejam introduzidos no romance, porém, há uma espécie de versão narrativa de uma imagem textual. Ao surpreender Martim na floresta, Iracema instintivamente o fere com uma flecha. A índia, no entanto, imediatamente corre para ampará-lo e curá-lo, quebrando em seguida a flecha que atirara. O impulso de Iracema ao fazer isso é sentimental: ela é movida pela pena, e reage ao sentimento que lê estampado no rosto de Martim. A linguagem simbólica de gestos e imagens aparece, assim, aliada à linguagem muda das emoções, que está calcada na empatia, e cuja transparência, desse modo, ela compartilha. Tanto a expressão de Martim quanto as ações de Iracema falam eloquentemente nesse trecho do romance, revelando o caráter dos dois personagens e sua moral. Se há um elemento convencional nessa comunicação - a quebra da flecha é um símbolo de amizade para o povo de Iracema - ele está calcado num gesto de significado inequívoco, que, dado o seu contexto, não parece arbitrário: a imagem parece natural e assume um significado universal, que pode ser lido por

18. Um exemplo retirado de $A$ viuvinha, publicado no mesmo ano de $O$ Guarani:

"Quando uma planta delicada nasce entre a sarça, muitas vezes o fogo queima-lhe a rama e o hastil; ela desaparece, mas não morre, que a raiz vive na terra; e às primeiras águas brota e pulula com toda a força de vegetação que incubara no tempo de sua mutilação.

O coração de Carolina fez como a planta." (ALENCAR. A viuvinha, p. 44).

19. ALENCAR. Iracema, p. 196.

20. ALENCAR. Iracema, p. 197. 
todos. ${ }^{21}$ A insistente associação de Iracema à natureza, além disso, mostra que estamos diante de uma manifestação da linguagem "natural" do primitivo. Antes de mais nada, a linguagem figurada em Alencar, como a linguagem transparente calcada em manifestações físicas da tradição sentimental, é ato. São as ações do corpo que falam, formando uma imagem, e é na superfície do corpo que se dá a comunicação.

Essa dinâmica se esconde por trás de boa parte dos símiles empregados por Alencar em Iracema. Neles, a natureza também gesticula: "A fronte reclinara e a flor do sorriso expandia-se como o nenúfar ao beijo do sol"; "o coração lhe tremia nos lábios, como gota de orvalho nas folhas do bambu"; "a filha do Pajé estremeceu. Assim estremece a verde palma, quando a haste frágil foi abalada; rorejam do espato as lágrimas da chuva, e os leques ciciam brandamente"; "Martim amparou o corpo trêmulo da virgem; ela reclinou languidamente sobre o peito do guerreiro, como o tenro pâmpano da baunilha que enlaça o rijo galho do angico"; "Esta palavra foi como um sopro de tormenta. A cabeça do mancebo vergou e pendeu sobre o peito". Estes são apenas alguns exemplos, retirados de duas páginas de Iracema. ${ }^{22}$ Em todos eles, a própria natureza parece demonstrar seus sentimentos através de ações. Ela é como um grande corpo que chora, sorri, estremece, reproduzindo o repertório de gestos expressivos da tradição sentimental. De fato, a natureza em Iracema frequentemente é dotada de sentimentos: "Em torno carpe a natureza o dia que expira. Soluça a onda trépida e lacrimosa; geme a brisa na folhagem; o mesmo silêncio anela de opresso". ${ }^{23}$ No mecanismo do símile, esses sentimentos da natureza são colocados lado a lado com os sentimentos dos personagens, e os dois grupos reverberam entre si. Essa passagem em que a tristeza da própria natureza é posta em destaque é seguida pouco depois por um símile em que esse pesar é ligado a Iracema, que se torna figurativamente um dos elementos naturais que sofrem: "Iracema dobrou a cabeça sobre a espádua, como a tenra palma da carnaúba, quando a chuva peneira na várzea”. ${ }^{24}$ O processo de

21. Calder indica que a crença na universalidade da linguagem "primitiva", uma consequência de sua transparência, também era difundida no discurso oitocentista sobre a linguagem natural. CALDER. Encounters with the Other, p. 36.

22. ALENCAR. Iracema, p. 203, p. 205.

23. ALENCAR. Iracema, p. 201.

24. ALENCAR. Iracema, p. 202. 
identificação da empatia sentimental, assim, é constantemente posto em ação nos símiles, que colocam em circulação sentimentos íntimos postos às claras em imagens concretas. Parte da ilusão de transparência almejada pela literatura sentimental deriva justamente dessa empatia, pois, como John Mullan indica em sua análise de Laurence Sterne, ela estabeleceria uma ligação entre os indivíduos e suas diferentes percepções. $^{25}$ O próprio leitor é convidado a participar dessa circulação, principalmente nos momentos em que os símiles redobram o espetáculo de um corpo sofredor, que se torna, assim, objeto de compaixão: "Do seio das brancas areias escaldadas pelo ardente sol, manava uma água fresca e pura; assim destila a alma do seio da dor lágrimas doces de alívio e consolo"; "Ai da esposa!... Sentiu já o golpe no coração e, como a copaíba ferida no âmago, destila lágrimas em fio". ${ }^{26}$ Muitos desses símiles têm o poder de duplicar e intensificar a carga emocional da narrativa e muitas vezes surgem em pontos de crise no enredo do romance, como na passagem em que Iracema dobra a cabeça sobre o peito como a carnaúba fustigada pela chuva, ao perceber que Martim começa a perder sua afeição por ela. Sendo assim, uma grande quantidade desses símiles funciona como os tableaux sentimentais.

Como os tableaux, os símiles de Alencar em Iracema suspendem por um instante o movimento da narrativa, criando um efeito de atemporalidade. Um dos termos da comparação estabelecida através do símile, que compreende os gestos ou o movimento interno dos personagens, é narrado no pretérito, enquanto o outro termo, que envolve os elementos da natureza, é descrito usandose o presente. Essa técnica não só tem o efeito de imobilizar a atitude dos personagens, colocando-a para a contemplação do leitor, ampliando a pausa necessária para a sua reação emocional, mas também cria uma sensação de imediatismo, que traz os eventos narrados no passado para o presente, como se eles estivessem se desenrolando diante dos olhos do leitor no momento em que acontecem, eliminando o efeito distanciador imposto por uma narrativa no pretérito - cria, portanto, a ilusão de uma suspensão temporária de um dos efeitos de intermediação entre os eventos narrados e o leitor. Mais ainda, o uso do presente ligado à apresentação de elementos naturais nos símiles coloca aquilo que há de efêmero na narrativa no âmbito de processos permanentes e universais, facilmente

25. MULLAN. Sentiment and Sociability: The Language of Feeling in the Eighteenth Century, p. 161.

26. ALENCAR. Iracema, p. 237, p. 238. 
observáveis. Ele tem, assim, um efeito retórico importante: aponta para uma verdade universal e inquestionável, verificada na presença de uma imagem concreta, imediatamente acessível em fenômenos naturais. Isso é particularmente importante nos pontos em que os símiles traduzem movimentos psíquicos ou emocionais, que são despidos de sua possível ambiguidade, já que são apresentados como equivalentes a processos observáveis na natureza. Assim como a natureza pode ser lida, pois se manifesta na superfície e é palpável, processos internos, que em princípio permaneceriam ocultos, também podem ser lidos da mesma forma, pois, na lógica de Iracema, a psique e a natureza têm o mesmo funcionamento, como se pode ver no símile a seguir:

O imbu, filho da serra, se nasce na várzea porque o vento ou as aves trouxeram a semente, vinga achando boa terra e fresca sombra; talvez um dia cope a verde folhagem e enflore. Mas basta um sopro do mar, para tudo murchar. As folhas lastram o chão; as flores, leva-as a brisa. Como o imbu na várzea, era o coração do guerreiro branco na terra selvagem. ${ }^{27}$

Os símiles de Alencar, portanto, possuem um forte componente didático. Neles, a presença de uma imagem clara desencoraja a interpretação. Seu sentido deve ser unívoco, imediatamente perceptível, longe das dúvidas e das ambiguidades que um processo interpretativo sempre pode gerar. Na verdade, os símiles são um dos mecanismos de que Alencar se utiliza para controlar a interpretação do leitor, guiando sua leitura, se certificando de que os processos internos de seus personagens estão sempre acessíveis e claramente explicitados.

Se, como observa M. Cavalcanti Proença, os símiles de Alencar tornam "concreta a abstração, e visível o invisível", ${ }^{28}$ talvez possamos ver o ápice desse processo na cena em que Iracema e Poti pintam ritualisticamente o corpo de Martim, cobrindo-o com representações pictóricas de seus atributos. Como o vestido branco de Lúcia, as pinturas, em vez de tornarem o corpo de Martim mais opaco ao recobri-lo, tornam-no transparente, trazendo as características morais do personagem para a superfície da pele. Parecemos estar diante de um efeito semelhante àquele pretendido por Richardson, em Clarissa, segundo Dorothea

27. ALENCAR. Iracema, p. 237.

28. PROENÇA. José de Alencar na literatura brasileira, p. 59. 
von Mücke: uma fusão dos atos de ler, ver e escrever, contornando a intermediação do signo e a fisicalidade do corpo enquanto objeto, estabelecendo-se uma representação transparente. ${ }^{29}$ No entanto, o que temos aqui não é um corpo ausente representado por um texto, mas um corpo que se torna o próprio texto que deveria representá-lo. Ao contrário do que ocorre em Clarissa, onde, como argumenta von Mücke, se cria na mente do leitor a presença ilusória de um corpo que na verdade está ausente, nesse trecho de Iracema se dá o apagamento alegórico da distância entre representante e representado. O texto é a presença de um corpo, mas de um corpo que se torna transparente, como o corpo da cortesã redimida em Lucíola. Pode-se ver aqui o ápice do desejo de Alencar pela fantasia de uma linguagem transparente através da criação de uma linguagem figurada que, como na ficção sentimental do século XVIII, engendra uma presença total do objeto que ela representa. ${ }^{30}$

Paradoxalmente, no caso da pintura do corpo de Martim, isso se dá através de uma intensificação da materialidade da linguagem, que se torna duplamente concreta: primeiro ao ser reduzida a pictogramas, depois ao ter sua materialidade reforçada ao ser associada à tinta, ao movimento dos pincéis, à pele. No entanto, como indiquei acima, isso só é possível porque a linguagem deixa de ser um meio de intermediação para se tornar a própria presença do objeto representado. Uma visão semelhante da linguagem pode ser percebida em Pamela, também de Samuel Richardson, um dos textos fundadores do romance sentimental na Inglaterra. A maior parte da narrativa de Pamela é formada pelas cartas que a protagonista escreve para os pais relatando as tentativas de seu patrão, Mr. B., de seduzi-la, às quais Pamela resiste heroicamente, a fim de preservar sua virtude. Num determinado ponto do romance, Pamela se vê obrigada a costurar suas cartas, que haviam se tornado um diário pessoal, dentro de suas saias, para escondê-las de Mr. B., que queria lê-las. Ao descobrir isso, Mr. B. ameaça despir Pamela para

29. VON MÜCKE. Virtue and the Veil of Illusion: Generic Innovation and the Pedagogical Project in Eighteenth-Century Literature, p. 91.

30. VON MÜCKE. Virtue and the Veil of Illusion: Generic Innovation and the Pedagogical Project in Eighteenth-Century Literature, p. 131. Essa busca pela presença do objeto representado por meio de sua evocação através de uma imagem tem uma origem ainda mais antiga que a tradição sentimental: Roland Barthes descobre o mesmo processo nos Exercícios de Ignacio de Loyola. Para Barthes, a imagem tem sempre um elemento dêitico: ela sempre aponta para a materialidade do referente e nos traz sua presença ilusória. Ver BARTHES. Sade, Fourier, Loyola, p. 68. 
descobri-las. Buscar as cartas equivale a explorar o corpo de Pamela, pois ambos agora estão identificados. Ter acesso às cartas significa ter acesso à própria Pamela.

Um outro exemplo de um texto associado à tradição sentimental em que se dá destaque a uma linguagem natural, concreta e transparente é Lettres d'une Péruvienne, de Françoise de Graffigny. Como nos romances indianistas de Alencar, essa linguagem também é associada aos nativos da América, desta vez aos incas da época da conquista espanhola. Zilia, a protagonista do romance de Graffigny, uma princesa inca raptada por espanhóis e depois levada para a França, conta a seu antigo amante, Aza, a história de seu aprisionamento através de quipos, cordões coloridos com nós utilizados pelos incas para registrar suas finanças, o número de seu povo ou até mesmo, segundo a autora, as ações memoráveis de seus líderes. ${ }^{31}$ Zilia emprega os quipos para relatar suas impressões dos franceses, seus pensamentos e seus sentimentos. O que imediatamente chama a atenção do leitor é a quantidade e a complexidade de informações que Zilia consegue transmitir através dos quipos, um meio que obviamente não é adequado para carregar tanto significado. Isso provavelmente se deve à condição dos quipos como um meio de comunicação transparente, capazes de evocar tudo o que ocorre no interior de Zilia porque supostamente dão total acesso à sua alma. ${ }^{32}$ Em Lettres d'une Péruvienne, os quipos são um tipo de linguagem extremamente concreta, que pode ser literalmente manuseada: "os mesmos nós que te darão novas da minha existência, ao mudar de forma entre as tuas mãos, me instruirão de teu destino". 33 Nos quipos, mensagem e resposta mantêm uma unidade, pois têm a mesma substância, que simplesmente é atada de formas diferentes por cada amante: são os mesmos cordões que vão e voltam entre Zilia e Aza. Como no caso da pintura sobre o corpo de Martim, porém, ao se tornar material, é como se o meio deixasse de existir: o quipo não é o meio para uma mensagem, ele é a mensagem. Na lógica de Lettres d'une Péruvienne, Zilia está sendo literal ao se referir ao quipo

31. GRAFFIGNY. Lettres d'une Péruvienne, p. 12-13, p. 18-19.

32. Claire Jaquier chama atenção para a utilização dos quipos como uma forma de linguagem transparente em Lettres d'une Péruvienne. Ver JAQUIER. L'erreur des désirs: romans sensibles au XVIIIe siècle, p. 76.

33. "Les mêmes nœuds qui t'apprendront mon existence, en changeant de forme entre tes mains, m'instruiront de ton sort." GRAFFIGNY. Lettres d'une Péruvienne, p. 21. Tradução minha. 
como "o tecido misterioso dos meus pensamentos", ou quando declara: "ao desatar os segredos de teu coração, o meu se banha num mar perfumado". ${ }^{34}$

Apesar de o quipo ser o exemplo mais marcante de uma forma de comunicação transparente e não verbal em Lettres d'une Péruvienne, outras formas de comunicação transparente aparecem no romance, como a música, à qual Zilia atribui um significado universal, e que ela associa à natureza (ao contrário da linguagem verbal, que ela considera artificial, uma invenção humana muitas vezes ininteligível). Além disso, no romance há inúmeros exemplos de imagens concretas que às vezes parecem prefigurar os símiles de Alencar: "Assim como a rosa recebe sua cor brilhante dos raios do Sol, os atrativos que vês no meu espírito e nos meus sentimentos não são mais do que as dádivas de teu gênio luminoso". 36 Mais tarde, nos romances de Chateaubriand, este se tornaria o estilo que caracterizaria a fala dos índios. Em Atala, sua manifestação serve para lembrar que Chactas, o narrador, apesar de ser, nas suas próprias palavras, um "selvagem civilizado", ainda retém muitas das características de um índio, incluindo sua maneira de falar, que é um sinal do elo que ele ainda mantém com a natureza. Esse tipo de linguagem imagística, porém, ressoa em romances sentimentais que não têm nenhuma ligação direta com a tradição indianista. Um símile de estrutura semelhante às dos empregados por Alencar ocorre, por exemplo, em Élisabeth, ou les exilés de Sibérie, de Sophie Cottin:

Elisabeth, escondida atrás de sua mãe, observava acanhada por cima de seu ombro para ver se o ar e a fisionomia do governador prometiam bondade o suficiente para que ela ousasse se mostrar a ele. Assim a tímida pomba, antes de sair do ninho, ergue a cabeça entre as folhas e

34. "Le mystérieux tissue de mes pensées"; "En dénouant les secrets de ton cœur, le mien se baigne dans un mer parfumé". GRAFFIGNY. Lettres d'une Péruvienne, p. 22. Tradução minha.

35. GRAfFignY. Lettres d'une Péruvienne, p. 75-76.

36. "Ainsi que la rose tire sa brillante couleur des rayons du Soleil, de même les charmes que tu trouves dans mon esprit et dans mes sentiments ne sont que les bienfaits de ton génie lumineux". GRAFFIGNY. Lettres d'une Péruvienne, p. 23. Tradução minha. 
olha muito o tempo para verificar se a pureza do céu lhe promete um dia sereno. ${ }^{37}$

Os símiles de Alencar, assim, são fruto de uma tradição mais ampla, que vai além daquela do romance indianista e que é pautada pela busca de uma linguagem transparente na qual a intermediação do meio deve ser reduzida ao mínimo. Trata-se de uma tradição que remonta ao século XVIII, quando, de acordo com David Marshall, buscava-se um ideal de leitura que seria análogo à experiência de testemunhar um espetáculo comovente. O texto deveria, então, criar a ilusão de que o leitor estava sendo confrontado com uma imagem, pois o apelo ao sentido da visão seria a maneira mais eficiente de envolver e comover o leitor. Ao mesmo tempo, a criação dessa visão ilusória (a criação de uma imagem através do texto) traria também a presença ilusória daquilo que é representado. ${ }^{38}$ De fato, os símiles de Alencar revelam o desejo de eliminar o meio da linguagem escrita, substituindo-a por imagens que evocam sensações e associações no leitor. Às vezes, as imagens se sobrepõem ao que é dito, como se as palavras, despidas de qualquer apelo figurativo, não fossem suficientes, ou fossem insatisfatórias:

De longe viram Iracema, que viera esperá-los à margem de sua lagoa da Porangaba. Caminhou para eles com o passo altivo da garça que passeia à beira d'água; por cima da carioba trazia uma cintura das flores da maniva que era o símbolo da fecundidade. Colar das mesmas cingia-lhe o colo e ornava os rijos seios palpitantes.

Travou a mão do esposo e a impôs no regaço:

- Teu sangue já vive no seio de Iracema. Ela será mãe de teu filho! ${ }^{39}$

Não basta a Iracema comunicar a Martim que está grávida de um filho seu; é preciso o gesto de colocar as mãos do esposo sobre o seu regaço, é preciso a metonímia do sangue de Martim que vive em seu seio, é preciso cobrir-se de

37. "Élisabeth, cachée derrière sa mère, regardait timidement par-dessus son épaule si l'air et la physionomie du gouverneur annonçait assez de bonté pour qu'elle osât s'ouvrir à lui. Ainsi la craintive colombe, avant de sortir de son nid, élève sa tête entre les feuilles, et regarde longtemps si la pureté du ciel lui promet un jour serein." COTTIN. Élisabeth, ou les exilés de Sibérie, p. 88. Tradução minha.

38. MARSHALL. The Surprising Effects of Sympathy, p. 19.

39. ALENCAR. Iracema, p. 231. 
flores que simbolizam a fertilidade e já anunciam o seu estado com uma imagem. No entanto, também é preciso explicar com palavras o significado das flores. A busca de uma linguagem de imagens permanece como um desejo que em última instância é inatingível, pois, como Marshall observa a respeito do romance do século XVIII, ela exige algo que o romance não pode fornecer, pois é estruturado apenas por palavras: a presença imediata do gesto e da imagem. ${ }^{40}$ Em Alencar, esse fracasso, essa frustração decorrente do paradoxo de criar uma linguagem puramente imagística através de palavras, se manifesta na própria proliferação dos símiles, no seu excesso e, muitas vezes, na sua redundância, como se a repetição pudesse aumentar a intensidade das imagens, afogando o texto em sensações visuais, na busca de um ideal que nunca chega a se concretizar completamente. No entanto, cada imagem evoca e encena esse ideal.

The transparency of the concrete: figurative language in Iracema

Abstract: Taking as its starting point a passage from the novel Lucíola, by José de Alencar, this article discusses the similes employed by Alencar in his Indianist novels and, more specifically, in Iracema. The passage from Lucíola analyzed here offers one of the keys to understand the figurative language used by Alencar in his Indianist novels: the search for a transparent language, based on images and associated with the primitive and with nature. This paper will show that the search for this kind of language is part of a long sentimental tradition originating in eighteenth-century Europe which still influences Alencar's work. Sentimental conventions related to sensibility and sympathy are behind the similes created by Alencar in Iracema, which are an example of his search for an expressive kind of language that would erase the intermediation of verbal language.

Keywords: Transparency, Images, Sentimental literature.

40. MARSHALL. The Surprising Effects of Sympathy, p. 39. 


$$
\text { Referências }
$$

ALENCAR, José de. A viuvinha. 1857. In: A viuvinha e Cinco Minutos. 34. ed. Rio de Janeiro: Ediouro, 2000. p. 13-50.

ALENCAR, José de. Iracema: lenda do Ceará. 1865. In: Obra completa, vol. 3. Rio de Janeiro: José Aguilar, 1958. p. 191-266.

ALENCAR, José de. Lucíola. 1862. 16. ed. São Paulo: Ática, 1992.

BARKER-BENFIELD, G. J. The Culture of Sensibility: Sex and Society in EighteenthCentury Britain. 1992. Chicago: Un. of Chicago Press, 1996.

BARTHES, Roland. Sade, Fourier, Loyola. Paris: Editions du Seuil, 1971.

CALDER, Martin. Encounters with the Other: A Journey to the Limits of Language through Works by Rousseau, Defoe, Prévost and Graffigny. Amsterdã; Nova York: Rodopi, 2003.

CHATEAUBRIAND, François-René de. Atala. 1801. In: Atala. René. Les Aventures du dernier Abencerage. Paris: Gallimard, 2001. p. 37-137.

COHEN, Margaret. The Sentimental Education of the Novel. Princeton: Princeton UP, 1999.

COTTIN, Sophie. Élisabeth, ou les exilés de Sibérie. 1806. In: Euvres completes de Mme. Cottin, vol. 12. Paris: Ménard et Desnne, fils, 1824, p. 1-224. Disponível em: http://gallica.bnf.fr/. Acessado em: 4 de abril de 2006.

DENBY, David J. Sentimental Narrative and the Social Order in France, 1760-1820. Cambridge: Cambridge UP, 1994.

EAGLETON, Terry. The Rape of Clarissa: Writing, Sexuality and Class Struggle in Samuel Richardson. Minneapolis: Un. of Minnesota Press, 1982.

FRIED, Michael. Absorption and Theatricality: Painting and Beholder in the Age of Diderot. Chicago: Un. of Chicago Press, 1988.

GRAFFIGNY, Françoise de. Lettres d'une Péruvienne. 1747. 4. reimpressão. New York: MLA, 2002.

JAQUIER, Claire. L'erreur des désirs: romans sensibles au XVIII 'eiècle. Lausanne: Payot Lausanne, 1998.

MARSHALL, David. The Surprising Effects of Sympathy: Marivaux, Diderot, Rousseau, and Mary Shelley. Chicago: The University of Chicago Press, 1988.

MÜCKE, Dorothea E. von. Virtue and the Veil of Illusion: Generic Innovation and the Pedagogical Project in Eighteenth-Century Literature. Stanford: Stanford UP, 1991.

MULLAN, John. Sentiment and Sociability: The Language of Feeling in the Eighteenth Century. New York: Oxford UP, 1988.

PROENÇA, M. Cavalcanti. José de Alencar na literatura brasileira. Rio de Janeiro: Civilização Brasileira, 1966.

RICHARDSON, Samuel. Pamela; or, Virtue Rewarded. 1740-41. London: Penguin, 1985.

ROUSSEAU, Jean-Jacques. Discours sur l'origine et les fondemens de l'inégalité parmi les hommes. 1755. In: Euvres complètes, v. 3. Paris: Gallimard, 1964.

SANTIAGO, Silviano. Alegoria e palavra em Iracema. Luso-Brazilian Review, vol. 2, p. 55-68, 1965. 
SPACKS, Patricia Meyer. Ambiguous Practices. In: TODD, Dennis; WALL, Cynthia (Org.). Eighteenth-Century Genre and Culture: Serious Reflections on Occasional Forms. Newark: Un. of Delaware Press; Londres: Associated Un. Presses, 2001. p. $150-164$.

STAROBINSKI, Jean. Jean-Jacques Rousseau: La transparence et l'obstacle, suivi de Sept essais sur Rousseau. 1971. Paris: Gallimard, 2000. 